\title{
ESTUDO DE CASO SOBRE A DINÂMICA DO MERCHANDISING EM PDV SOB ÓTICA DO DESIGN DE INTERIORES
}

\section{Lennon Gomes}

Associação de Ensino e Cultura de Mato Grosso do Sul - AEMS, Curso de Arquitetura e Urbanismo, Três Lagoas - MS.

\section{RESUMO}

Este trabalho buscou analisar quatro estudos de casos através de elementos ambientais baseados nas técnicas do merchandising do ponto de venda, pelo fato de que o merchandising é cada vez mais utilizado nos comércios varejistas de autosserviço. O objetivo geral está na conciliação multidisciplinar entre a Comunicação Visual (Merchandising), Psicologia Ambiental e Design de Interiores. A metodologia utilizada nesta pesquisa está baseada em análises sucessivas, por meio de etapas de investigação científica objetiva bibliográfica. A investigação passou para a fase prática, por meio de pesquisa de campo, levantamentos de estudos preliminares em lojas de shoppings centers, através de estudos feitos por Baker e outros (2002) e Bitner (1992), considerando as dimensões e elementos tangíveis, para contribuir e desenvolver uma análise crítica da produção dos espaços comerciais do varejo, permitindo assim, tendo este trabalho como base de referência para futuros projetos voltados para a área comercial.

Palavras-chave: Merchandising; Design de Interiores; Comunicação visual;

\section{CASE STUDY ON THE DYNAMICS IN MERCHANDISING POS IN PERSPECTIVE OF INTERIOR DESIGN}

\begin{abstract}
This study aimed to analyze four case studies by environmental elements based on point of sale merchandising techniques, the fact that product placement is increasingly used in trades selfservice retailers. The overall objective is the multidisciplinary Reconciling Visual Communication (Merchandising), Environmental Psychology and Interior Design. The methodology used in this research is based on successive analyzes, through steps objective scientific research literature. The investigation went to the practice phase, through field research, surveys of preliminary studies in shopping mall stores, through studies by Baker and others (2002) and Bitner (1992), considering the dimensions and tangible to contribute and develop a critical analysis of the production of commercial retail spaces, thus taking this work as the basis for future projects for the commercial area.
\end{abstract}

Keywords: Merchandising; Interior Design; Visual communication; 


\section{INTRODUÇÃO}

O conceito de merchandising tem significado amplo, apontado como qualquer técnica, ação, ou material promocional usado no ponto de venda, que proporcione informação e melhor visibilidade dos produtos, marcas e serviços, com o propósito de motivar e influenciar as decisões de compra dos consumidores.

Para compreender o consumidor é preciso entender a relação existente entre os diversos significados sociais e culturais compartilhados e os significados próprios de cada indivíduo. Porém, como os processos sociais e culturais são dinâmicos e mutativos, os significados de consumo são continuamente reestruturados ao longo do tempo, tornando esse fenômeno complexo.

No ponto de venda que ocorre o contato entre cliente, produto e marca antes da decisão de compra, sendo este um dos momentos mais importantes da relação entre consumidor e empresa. Ponto de venda é o local que reúne os três principais fatores de efetivação da compra: o produto/serviço, o consumidor, e o capital. É da importância do cliente no ponto de venda que decorre a relevância do uso do merchandising.

O objetivo geral está na conciliação multidisciplinar entre a Comunicação Visual (Merchandising), Psicologia Ambiental e Design de Interiores, buscando um entendimento na busca da otimização ${ }^{1}$ dos espaços comerciais. Partindo para os objetivos específicos, serão tratados pontos que abrangem a questão da comunicação dos espaços internos das lojas de varejo, buscando um entendimento na busca de estratégias de valorização e destaque de produtos para uma maior eficiência na composição projetual de espaços comerciais, atingindo o público-alvo de modo a aumentar as chances de compra dos produtos expostos.

\section{METODOLOGIA}

A metodologia utilizada nesta pesquisa está baseada em análises sucessivas, por meio de etapas de investigação científica objetiva. Na primeira fase, buscou-se o foco na linha teórica, assim como levantamentos bibliográficos, vinculados ao merchandising, espaços comerciais, comportamento social, entre outros, para auxiliar no entendimento específico deste trabalho para contribuir com o entendimento da relação do cliente com o Design de Interior aplicada no Comercio do Varejo. A investigação passou para a fase prática, por meio de pesquisa de campo, por meio de registros de fotos, base teórica aplicada no design e seus intencionais projetuais através de cores, formas, linhas, materiais, iluminação, ergonomia entre outros, através de estudos feitos por Baker e outros (2002) e Bitner (1992), considerando as dimensões e elementos tangíveis, para contribuir e desenvolver uma análise crítica da produção dos espaços comerciais do varejo.

\section{OBJETIVOS}

O objetivo geral está na conciliação multidisciplinar entre a Comunicação Visual (Merchandising), Psicologia Ambiental e Design de Interiores, buscando um entendimento na busca da otimização ${ }^{2}$ dos espaços comerciais.

Partindo para os objetivos específicos, serão tratados pontos que abrangem a questão da comunicação dos espaços internos das lojas de varejo, buscando um entendimento na busca de estratégias de valorização e destaque de produtos para uma maior eficiência na composição projetual de espaços comerciais, atingindo o público-alvo de modo a aumentar as chances de compra dos produtos expostos.

${ }^{1}$ Criar condições mais favoráveis para; tirar o melhor partido possível.

${ }^{2}$ Criar condições mais favoráveis para; tirar o melhor partido possível. 


\section{REVISÃO DA BIBLIOGRAFIA}

A partir das descobertas de Mehrabian e Russel (1974) sobre a atmosfera dos ambientes comerciais, os autores apresentaram conceitos concretos dos efeitos causados pela atmosfera na emoção das pessoas. Portanto, evidenciaram de que os elementos do ambiente geram reações emocionais que se transformam em comportamentos muitas vezes inexplicáveis do ponto de vista cognitivo (FEIJó, 2010).

Conforme Blessa (2003), ponto de venda é o local que reúne os três principais fatores de efetivação da compra: o produto/serviço, o consumidor, e o capital. É da importância do cliente no ponto de venda que decorre a relevância do uso do merchandising.

A apresentação de produtos e ambientes mostrou o efeito das decisões de merchandising sob o argumento de que o valor de compra é uma resposta interna do consumidor aos efeitos da atmosfera da loja, dividindo o ambiente do PDV em quatro aspectos: desenho exterior, condições ambientais, desenho interior e dimensão social (BLESSA, 2003).

Usando um método experimental, Sampaio e outros (2009) confirmaram que os elementos de design (organização do ambiente, exposição das mercadorias, adequação da iluminação e facilidade de localização) têm efeito positivo na percepção do valor de compra. Sobre valores hedônicos, indicados pelas expressões de encantamento, divertimento, excitação e espontaneidade, as referências aos ambientes onde existem sofás, vegetação, iluminação natural e uso de cores são mais significativas. Entre os elementos de design que apresentaram impactos positivos e significativos sobre o valor de compra percebido pelos clientes, aquele que se mostrou com maior magnitude nas três situações propostas, foi propriamente a exposição de mercadorias com facilitação do manuseio dos produtos (SAMPAIO; et. al. 2009).

O layout do espaço físico, Bitner (1992), diz respeito à disposição dos móveis e equipamentos, a forma e ao tamanho destes itens e às relações espaciais entre eles, sendo uma importante estratégia para o estímulo à compra por impulso e à atratividade do espaço como um todo. Segundo classificação de Sherman e outros (1997) para as características de layout, em: organização do ambiente, dimensão dos corredores, circulação sem obstáculos, exposição das mercadorias e limpeza do ambiente (SAMPAIO e outros, 2009).

Nesse sentido, seguindo as proposições de Sherman e outros (1997), solidificadas pelos resultados da fase qualitativa em seu trabalho, quanto ao layout, Sampaio e outros (2009) sugerem que: o nível de organização do espaço físico afeta positivamente a percepção do valor de compra por parte do cliente; a limpeza do ambiente afeta positivamente a percepção do valor de compra por parte do cliente; a dimensão dos corredores afeta positivamente a percepção do valor de compra por parte do cliente; a possibilidade de circulação sem obstáculos afeta positivamente a percepção do valor de compra por parte do cliente; a adequada exposição das mercadorias afeta positivamente a percepção do valor de compra por parte do cliente.

Por outro lado, Sampaio e outros (2009) consideram a iluminação como um fator visual de design e que pode ter a função de estabelecer o posicionamento do empreendimento, considera-se que a adequação da iluminação afeta positivamente a percepção de valor de compra.

\section{ESTUDO DE CASO}

O estudo se volta para quatro lojas de grande porte varejista, com intuito de analisar a dinâmica do espaço comercial a fim de evidenciar, sob a ótica do design de interiores, as técnicas de merchandising utilizados nos ambientes internos apontados anteriormente. Vale reforçar que as quatro lojas estão localizadas no PrudenShopping.

O levantamento de campo foi através de fotos e análise espacial no local, relacionando-os as análises com levantamento bibliográfico, utilizando principalmente os estudos de Baker e outros (2002) que considera fatores ambientais, sociais e do design, e Bitner (1992) considera a evidência física em três dimensões: ambiente; espaço-função; sinalização, símbolos, objetos. Os 
elementos tangíveis analisados foram: fatores ambientais visíveis: materiais utilizados, cores, luzes; Fatores visuais de design/ interno: sinais e símbolos, layout, merchandising (disposição de mercadorias), equipamentos, expositores, móveis, estilo, decoração, arquitetura interna. Conforme Quadro 2.

Quadro 01. Dimensões e Elementos Tangíveis dos estudos de caso.

\begin{tabular}{|c|c|c|c|c|c|}
\hline \multicolumn{6}{|c|}{ DIMENSÕES E ELEMENTOS TANGÍVEIS } \\
\hline \multirow{2}{*}{ FATORES } & \multirow{2}{*}{ ELEMENTOS } & \multicolumn{4}{|c|}{$\begin{array}{ll} & \text { LOJAS } \\
\end{array}$} \\
\hline & & LOJA 1 & LOJA 2 & LOJA 3 & LOJA 4 \\
\hline \multirow{3}{*}{$\begin{array}{l}\text { Ambientais } \\
\text { visíveis }\end{array}$} & Materiais utilizados & $\begin{array}{c}\text { Ferro polido e } \\
\text { aglomerado com placa } \\
\text { vinilica }\end{array}$ & $\begin{array}{l}\text { Ferro com pintura } \\
\text { branca e cinza; } \\
\text { aglomerado com placa } \\
\text { vinilica; chapas } \\
\text { metálicas }\end{array}$ & $\begin{array}{c}\text { Ferro com pintura } \\
\text { cinza e preto; } \\
\text { aglomerado com placa } \\
\text { vinilica; chapas } \\
\text { metálicas brancas; } \\
\text { ACM }\end{array}$ & $\begin{array}{c}\text { Ferro; madeira; } \\
\text { tirantes em aço; } \\
\text { aglomerado com placa } \\
\text { vinilica; ferro polido; } \\
\text { chapas metálicas; } \\
\text { ACM }\end{array}$ \\
\hline & Cores & $\begin{array}{c}\text { Branco prevalece, } \\
\text { pouca madeira e preto }\end{array}$ & $\begin{array}{l}\text { Branco prevalece, } \\
\text { pouca madeira }\end{array}$ & $\begin{array}{l}\text { Branco, vermelho e } \\
\text { preto; pouco cinza e } \\
\text { madeira }\end{array}$ & $\begin{array}{c}\text { Branco; marrom; } \\
\text { amarelo; cinza; outras } \\
\text { cores nos cenários }\end{array}$ \\
\hline & Luzes & $\begin{array}{c}\text { Iluminação geral e } \\
\text { pouca focal }\end{array}$ & $\begin{array}{c}\text { Iluminação geral e } \\
\text { pouca focal }\end{array}$ & $\begin{array}{c}\text { Iluminação geral e } \\
\text { focal }\end{array}$ & $\begin{array}{l}\text { Iluminação geral e } \\
\text { focal }\end{array}$ \\
\hline \multirow{8}{*}{$\begin{array}{c}\text { Visuais de } \\
\text { Design/Interno }\end{array}$} & Sinais e símbolos & $\begin{array}{c}\text { Poucos sinais e } \\
\text { símbolos }\end{array}$ & $\begin{array}{c}\text { Grande quantidade de } \\
\text { sinais e símbolos }\end{array}$ & $\begin{array}{c}\text { Quase nulos os sinais } \\
\text { e símbolos }\end{array}$ & $\begin{array}{c}\text { Sinais e símbolos } \\
\text { pontuais }\end{array}$ \\
\hline & Layout & $\begin{array}{l}\text { Setorizado em } \\
\text { perpendicular }\end{array}$ & $\begin{array}{l}\text { Setorizado em } \\
\text { perpendicular }\end{array}$ & $\begin{array}{l}\text { Setorizado em } \\
\text { perpendicular } \\
\end{array}$ & $\begin{array}{l}\text { Setorizado em } \\
\text { perpendicular }\end{array}$ \\
\hline & $\begin{array}{l}\text { Disposição das } \\
\text { mercadorias }\end{array}$ & $\begin{array}{c}\text { Grupos de cores; } \\
\text { disposição vertical; } \\
\text { categoria de produtos; } \\
\text { simétrica e } \\
\text { assimétrica; } \\
\text { anatômica; } \\
\text { coordenada }\end{array}$ & $\begin{array}{c}\text { Grupos de cores; } \\
\text { disposição vertical; } \\
\text { categoria de produtos; } \\
\text { simétrica e } \\
\text { assimétrica; } \\
\text { anatômica; } \\
\text { coordenada }\end{array}$ & $\begin{array}{c}\text { Grupos de cores; } \\
\text { disposição vertical; } \\
\text { categoria de produtos; } \\
\text { simétrica e } \\
\text { assimétrica; } \\
\text { anatômica; } \\
\text { coordenada }\end{array}$ & $\begin{array}{c}\text { Grupos de cores; } \\
\text { disposição vertical; } \\
\text { categoria de produtos; } \\
\text { simétrica e } \\
\text { assimétrica; } \\
\text { anatômica; } \\
\text { coordenada }\end{array}$ \\
\hline & $\begin{array}{c}\text { Equipamentos e } \\
\text { expositores }\end{array}$ & $\begin{array}{c}\text { Grande quantidade de } \\
\text { expositores }\end{array}$ & $\begin{array}{c}\text { Grande quantidade de } \\
\text { expositores }\end{array}$ & $\begin{array}{c}\text { Grande quantidade de } \\
\text { expositores }\end{array}$ & $\begin{array}{c}\text { Grande quantidade de } \\
\text { expositores }\end{array}$ \\
\hline & Móveis & $\begin{array}{l}\text { Pouca quantidade: } \\
\text { ilha com prateleiras } \\
\text { horizontais; mesas } \\
\text { com tamanhos } \\
\text { diferentes }\end{array}$ & $\begin{array}{l}\text { Pouca quantidade: } \\
\text { mesas com tamanhos } \\
\text { diferentes; perfis } \\
\text { metálicos em chapas }\end{array}$ & $\begin{array}{l}\text { Pouca quantidade: } \\
\text { ilha de perfume e de } \\
\text { relógios em mdf com } \\
\text { placa vinilica; mesas } \\
\text { com tamanhos } \\
\text { diferentes; } \\
\text { expositores verticais } \\
\text { de chão }\end{array}$ & $\begin{array}{l}\text { Pouca quantidade: } \\
\text { mesas com tamanhos } \\
\text { diferentes; perfis } \\
\text { metálicos em chapas; } \\
\text { armários abertos; } \\
\text { carretel de madeira }\end{array}$ \\
\hline & Estilo & $\begin{array}{c}\text { Estilo popular, } \\
\text { acabamento simples; } \\
\text { moderno/ } \\
\text { contemporâneo }\end{array}$ & $\begin{array}{c}\text { Estilo popular, } \\
\text { acabamento simples; } \\
\text { jovem (informal); } \\
\text { moderno/ } \\
\text { contemporâneo }\end{array}$ & $\begin{array}{l}\text { Estilo classe média, } \\
\text { acabamento de } \\
\text { padrão médio; formal } \\
\text { contemporâneo }\end{array}$ & $\begin{array}{l}\text { Estilo classe média, } \\
\text { acabamento de } \\
\text { padrão médio; jovem } \\
\text { lúdico/ informal } \\
\text { contemporâneo }\end{array}$ \\
\hline & Decoração & Inexistente & Pouca & Pouca e localizada & Localizadas \\
\hline & Arquitetura interna & $\begin{array}{l}\text { Grande vão com pé } \\
\text { direito duplo; poucos } \\
\text { pilares; forro de gesso } \\
\text { acartonado; paredes } \\
\text { estruturadas em } \\
\text { painéis de mdp com } \\
\text { acabamento branco; } \\
\text { piso cerâmico }\end{array}$ & $\begin{array}{l}\text { Grande vão; poucos } \\
\text { pilares; forro de gesso } \\
\text { acartonado; paredes } \\
\text { estruturadas em } \\
\text { drywall com } \\
\text { acabamento branco; } \\
\text { piso cerâmico }\end{array}$ & $\begin{array}{l}\text { Grande vão; poucos } \\
\text { pilares; forro de gesso } \\
\text { acartonado; paredes } \\
\text { estruturadas em } \\
\text { drywall com } \\
\text { acabamento branco; } \\
\text { piso em porcelanato }\end{array}$ & $\begin{array}{l}\text { Grande vão; poucos } \\
\text { pilares; forro de gesso } \\
\text { acartonado; paredes } \\
\text { estruturadas em } \\
\text { painéis de mdp com } \\
\text { acabamento branco; } \\
\text { piso em porcelanato }\end{array}$ \\
\hline
\end{tabular}

Fonte: Autores (2015)

As possibilidades de circulação sem obstáculos foram consideradas não somente degraus, desníveis, objetos etc. foi considerado também a configuração do layout em corredores contínuos, com linhas retas, o que em todos os casos foi observado como adequado, contudo, a loja 3 e 4 , apresentam um maior número de pilares em seu interior, o que afeta esta condição de continuidade.

A adequação da exposição das mercadorias influencia diretamente na relação da mercadoria e cliente. Esta relação está apontada no Quadro 1, no tópico Visuais de 
Design/Interior, ponderando que, nos quatro casos, o fácil manuseio e prova das mercadorias, em todos os casos se mostrou adequado.

A adequação da iluminação também já observada no Quadro 1, em Ambientais Visíveis, revela uma maior preocupação por parte das lojas 3 e 4, as temáticas são pontuadas e acentuadas, os manequins, o destaque de novas peças, enfim, utilizam-se de recursos para valorizar a peça, o que não foi apresentado na loja 1 e 2.

A adequação da sinalização em um ambiente de varejo de autosserviço é fundamental, porém, como apresentado no Quadro 1, no tópico Visuais de Design/Interior, a variação entre as lojas revela que os sinais e símbolos são usados de acordo com o público alvo, promoções, valores, ofertas, últimas peças, enfim, foram mais utilizados na loja 2, revelando uma popularidade em seus produtos, no caso da loja 1 e 4, esses elementos eram poucos utilizados, o que revela um público de classe média, no caso da loja 3, estes elementos eram praticamente nulos, ou seja, sua intenção visual é de dar mais valor em sua mercadoria, o que torna seu público alvo de classe média/alta.

\section{CONSIDERAÇÕES FINAIS}

As pesquisas científicas abordadas neste trabalho mostraram em seus estudos que a técnica de merchandising é empregada nas lojas de autosserviços de varejo, tendo como objetivo influenciar diretamente o consumidor, tendo que ser considerado nos projetos do comércio varejista de autosserviço. Desenvolver a venda visual de autosserviço é fundamental pelo fato de não apresentarem vendedores para o atendimento, os produtos e o visual da loja têm um papel importante de comunicação com o cliente.

As diversas pesquisas sobre o comportamento em ambientes comerciais indicam que a atmosfera da loja pode influenciar os consumidores. O sentido da funcionalidade no desenho da loja deve ser de modo a permitir uma compra mais fácil e rápida, a fim de aumentar o valor funcional, ou seja, uma circulação satisfatória e de fácil localização visual.

Os padrões de materiais utilizados, também indicam o público alvo a ser considerado na loja, a atmosfera proporciona um estado emocional onde o indivíduo se sente à vontade para realizar a compra, valoriza o produto, portanto, as chances de compra aumentam ou diminuem através do ambiente constituído.

Os apontamentos indiciados neste trabalho nos revelaram a importância dos elementos do design inseridos em um ambiente conciliado com outras áreas de estudos como a comunicação visual e psicologia ambiental. Tendo como base os elementos tangíveis e as dimensões estudadas nos quatro casos conseguimos criar e/ou adequar espaços de venda com diferenciais e/ou limitando públicos alvo para atingir as vendas dos produtos. Atualmente, o mercado se depara com grande oferta, concorrência cada vez maior, consumidores exigentes e diversificados. Surgindo a necessidade de conhecer os gostos dos consumidores, segmentando-os.

\section{REFERÊNCIAS}

BAKER, J; PARASURAMAN, A; GREWAL, D; VOSS, G. B. The influence of multiple store environment cues on perceived merchandise value and patronage intentions. Journal of Retailing, v. 66, n. 2, p. 120-141, 2002. https://doi.org/10.1509/imkg.66.2.120.18470

BITNER, M. J. Servicescapes: the impact of physical surrounding on customers and employees. Journal of Marketing, v. 56, p. 57-71, April 1992. https://doi.org/10.2307/1252042

BLESSA, R. Merchandising no ponto de venda. São Paulo: Atlas, 2003. 
FEIJÓ, F. Efeito dos fatores de design do merchandising nas vendas em varejo. Dissertação (Mestrado em Gestão Empresarial) - Fundação Getúlio Vargas, Escola Brasileira de Administração Pública e de Empresas - EBAPE. 2010.

MEHRABIAN, A; RUSSEL, J. A. An approach to environmental psychology. Cambridge: MIT Press, 1974.

SAMPAIO, Cláudio Hoffmann; SANZI, Gianpietro; SLONGO, Luiz Antonio and PERIN, Marcelo Gattermann. Fatores visuais de design e sua influência nos valores de compra do consumidor. Rev. adm. empres. [online]. 2009, vol.49, n.4, pp. 373-386. ISSN 2178938X. http://dx.doi.org/10.1590/S0034-75902009000400002. https://doi.org/10.1590/S0034$\underline{75902009000400002}$

SHERMAN, E; MAT HUR, A; SMITH, R. B. Store environment and consumer purchase behavior: mediating role of consumer emotions. Psychology \& Marketing, v. 14, n. 4, p. 361-378, 1997. https://doi.org/10.1002/(SICI)1520-6793(199707)14:4<361::AID-MAR4>3.0.CO;2-7 